ARTIGOS

ESPAÇO, ECONOMIA E POPULAÇÃO

\title{
O SISTEMA URBANO DA BAHIA NO CONTEXTO DA EMERGÊNCIA DE NOVAS HIERARQUIAS URBANO-REGIONAIS
}

\author{
Leonardo Rodrigues Porto \\ Humberto Miranda \\ *Universidade Estadual de Campinas, Centro de Estudos do Desenvolvimento Econômico, Campinas, SP, Brasil.
}

\begin{abstract}
Resumo
Qual foi a evolução do sistema urbano baiano no contexto da urbanização brasileira pós-199o? O objetivo deste texto é analisar as transformações nas redes de cidades do estado da Bahia em período mais recente. Buscou-se caracterizar a Região de Influência de Salvador, cujas articulações espaciais extrapolam as divisas do próprio estado. Esse recorte constitui importante instrumento de compreensão da dinâmica urbano-regional. Na conclusão, apresenta-se uma reflexão sobre as novas determinações da hierarquia urbanoregional baiana.

Palavras-chave

Bahia; Rede Urbana; Hierarquias urbano-regionais.
\end{abstract}


ARTICLES

SPACE, ECONOMY AND POPULATION

\title{
THE URBAN SYSTEM OF THE STATE OF \\ BAHIA-BRAZIL IN THE CONTEXT OF THE EMERGENCE OF NEW URBAN-REGIONAL HIERARCHIES
}

\author{
Leonardo Rodrigues Porto \\ Humberto Miranda \\ *Universidade Estadual de Campinas, Centro de Estudos do Desenvolvimento Econômico, Campinas, SP, Brazil.
}

\begin{abstract}
The purpose of this text is to analyze the transformations in the urban network in the state of Bahia post-199o. We sought to characterize the Salvador's area of influence, whose spatial articulations go beyond the boundaries of the state itself. This cut is an important instrument for understanding the urban-regional dynamics. In conclusion, it is presented a reflection on the new determinations of the urban-regional hierarchy in Bahia.

Keywords

State of Bahia; Urban Network; Urban-regional hierarchies.
\end{abstract}




\section{O SISTEMA URBANO DA BAHIA NO CONTEXTO DA EMERGÊNCIA DE NOVAS HIERARQUIAS URBANO-REGIONAIS}

Leonardo Rodrigues Porto

Humberto Miranda

Introdução

A evolução do sistema urbano do estado da Bahia apresenta uma rede de cidades com importante adensamento populacional no litoral e na Região Metropolitana de Salvador (RMS) e com menor adensamento em poucas cidades de porte médio no interior do estado. A estruturação desse sistema urbano acompanha o movimento da urbanização brasileira desde os anos 1950, momento em que as principais hierarquias urbanas foram se constituindo a partir de duas metrópoles nacionais, São Paulo e Rio de Janeiro.

Como já não é possível caracterizar a estruturação do espaço nacional como decorrência exclusiva da industrialização (SANTOS, 1993) no período recente, novas determinações ganharam importância, conforme observa Cano (2011), algumas delas específicas a determinados espaços regionais. Quais foram as principais mudanças no sistema urbano baiano pós-1990?

Embora guarde características regionais específicas, referentes ao processo histórico de formação das diferentes regiões de um país continental como o Brasil e ao modo como cada região se inseria na divisão regional do trabalho, o sistema urbano baiano se renovou depois de 1988, com a entrada em vigor da nova Constituição Federal, que deu maior protagonismo a estados e municípios.

Todavia, as transformações do sistema urbano baiano no período posterior a 1980 se caracterizam por uma rede de cidades já consolidada, pela emergência de novas centralidades no interior do estado - com destaque para a cidade de Feira 
de Santana e o Polo Petrolina-Juazeiro - e pelo fortalecimento de centros de porte médio em decorrência de fatores econômicos (agronegócio no oeste e celulose no extremo sul) e institucionais (aumento das transferências governamentais).

O objetivo deste texto é analisar as transformações nas redes de cidades do estado da Bahia pós-1990. Para tanto, caracteriza-se a Região de Influência de Salvador (RIS), cujas articulações espaciais - traçadas pelos fluxos socioeconômicos - extrapolam as divisas estaduais, conforme demonstrado pelo Instituto Brasileiro de Geografia e Estatística (IBGE, 2008; 2013; 2020). A conformação da RIS expõe o comando da metrópole baiana e viabiliza o uso de novos recortes espaciais para a pesquisa acadêmica.

Sob uma perspectiva analítico-descritiva, o texto explora as características demográficas e econômicas desse sistema de cidades, abrindo frente para discutir, como agenda de pesquisa, as novas articulações espaciais que se impuseram àquele território. Partimos da pesquisa Regiões de Influência das Cidades-2007 (Regic), do IBGE (2008; 2013); em seguida, com o recorte espacial da RIS, foram levantados dados relativos aos aspectos demográficos e econômicos; na sequência, foi examinado o movimento de ganhos e perdas de centralidade das cidades baianas. Por fim, caracterizou-se o perfil socioeconômico do sistema urbano baiano.

O texto é composto de três seções além desta introdução. Na seção 1, serão discutidos alguns condicionantes que caracterizaram a dinâmica urbano-regional brasileira depois de 1990, com a abordagem de algumas interpretações que buscam esclarecer seu sentido contemporâneo. Na seção 2, analisam-se os rebatimentos desses condicionantes sobre o território baiano e seu sistema de cidades, e discutem-se os principais aspectos da atual configuração do sistema urbano da Bahia. Na seção 3, faz-se uma análise espacial mais integrada a respeito da RIS e de suas articulações territoriais. Por fim, apresentam-se as considerações finais.

\section{A dinâmica urbano-regional brasileira contemporânea}

Uma nova ordem de fatores viria a determinar o processo de desenvolvimento econômico e social do Brasil a partir da década de 1980. De acordo com Cano (2011), as transformações em curso na economia nacional e internacional adicionaram novos elementos às questões regional e urbana brasileiras. Em contraste com o período anterior, as últimas duas décadas do século XX e o início do século XXI foram marcados pela forma subordinada e passiva com que se desenvolveu a política econômica nacional (CANO, 2000), mas alguns nexos intrarregionais foram assegurados em boa medida pela estrutura de repartição do gasto público via sistema de transferências e por programas sociais e de investimentos públicos e privados até 2013 . 
O êxito das políticas de estabilização dos preços nos anos 1990 seria sustentado pela armadilha cambial e sua instabilidade implícita. Decorrem daí o uso de taxas de juros reais elevadas, mudanças na estrutura do balanço de pagamentos e uma nova onda de investimentos externos, sob a lógica das empresas transnacionais. Estas últimas, promotoras da guerra global entre lugares ${ }^{1}$, impõem uma dinâmica importadora que força a desestruturação de cadeias produtivas nacionais (CANO, 2000) e também resultam em adaptação política, mudanças institucionais, fiscais, trabalhistas, entre outras, que funcionam como "alavancas que os lugares lutam entre si para atrair novos empreendimentos” (SANTOS, 1999). Essa se tornou a essência do neoliberalismo econômico urbano por meio da valorização dos circuitos imobiliários.

Já nos anos 2000, destacam-se alguns avanços na estrutura social e de emprego no país, apesar da continuidade das principais diretrizes da política macroeconômica neoliberal. Esses avanços afetaram a distribuição de renda do Brasil, em especial após a adoção de políticas que geraram efeitos implícitos favoráveis ao desenvolvimento de regiões mais pobres (ganho real no valor do salário mínimo, aumento do crédito para investimento e consumo, crédito consignado, transferências de renda). Todavia, se o consumo foi bastante incrementado, faltaram elementos significativos de políticas de desenvolvimento industrial e tecnológico, com impactos nos setores primário e terciário, para que esses avanços fossem mais expressivos e duradouros (QUADROS, 2010; 2014). Isso permitiu o fortalecimento do capital de incorporação via articulação do setor da construção civil e do setor financeiro.

Nesse novo contexto, houve ampliação relativa da rede de proteção social, projetando o aumento continuado da demanda por políticas urbanas (infraestrutura e moradia) e por serviços sociais básicos nos estados e municípios (ORAIR, 2016). Entretanto, após a crise de 2008, mesmo com o país continuando a operar numa dinâmica social favorável, a despeito do cenário de baixo crescimento econômico, foi mal dimensionada ou subestimada a oferta de bens e serviços públicos e coletivos, a fim de compensar os efeitos das políticas neoliberais e/ou para avançar para além delas (BRANDÃO, 2015). As melhorias decorrentes do estímulo ao consumo familiar no combate aos efeitos da crise internacional se esgotaram a partir de 2013, com forte reversão após a crise econômica e política que se instaurou no país em 2015.

A melhora social articulou-se com a reconfiguração dos sistemas sociais do Brasil, com ênfase nas transferências monetárias de renda. No entanto, a agenda de melhorias pautou-se por programas sociais que estabeleceram com áreas pouco integradas ao mercado nacional maior vínculo com a mercantilização de vários

1. Termo cunhado por Milton Santos (1999). 
setores em que o Estado deveria ser o principal provedor (LAVINAS, 2014). Buscava-se o acesso dos mais pobres ao “direito a mínimos monetários”, mediante políticas sociais específicas, que foi a tônica da política assistencial brasileira nos anos 2000 e 2010. Essas condições mostraram-se incapazes de dar conta do caráter heterogêneo da estrutura social brasileira e da diversidade dos problemas regionais e urbanos, dada a fragilidade dessas conquistas diante de cenários econômicos adversos (LAVINAS, 2014).

Na região Nordeste, em particular, verificou-se que peculiaridades como a heterogeneidade, a diversidade e a complexidade de sua economia (MACEDO; MORAIS, 2011) promoviam maior diferenciação no espaço intrarregional, resultante tanto do seu processo histórico de ocupação como das novas demandas urbanas. As áreas de grande dinamismo tornam-se cada vez mais atuantes no mercado externo em fiel conexão com o padrão de reprodução do capital especializado em commodities e em serviços voltados ao turismo litorâneo, setor importante dentro do circuito imobiliário. Em contraste, as áreas de pouca densidade econômica, mais sensíveis às mudanças climáticas, aumentaram a demanda por políticas públicas, bens e serviços públicos e coletivos, mas não teriam chances de sustentar seu crescimento num cenário de reversão econômica e de maior restrição dos gastos do governo.

No rol dessas transformações, passaram a atuar novas determinações espaciais sobre o processo de urbanização brasileira, diferentes das que operavam no período pré-1980 (CANO, 2011). Uma questão que emerge desse processo refere-se às alterações verificadas na rede urbana brasileira. São mudanças mais intensas nas hierarquias urbanas desde 1990, as quais, em alguma medida, revelam o poder de mediação de cidades intermediárias nas áreas não metropolitanas de maior interesse capitalista e nas áreas interioranas mais dependentes de gastos e investimentos públicos. A combinação de fundo público, interesses imobiliários e logísticos, obras públicas e descentralização de serviços públicos (unidades de saúde e universidades, por exemplo) desempenha um papel nas centralidades de algumas cidades, influenciando nas hierarquias urbanas.

De forma geral, depois de 1990, o maior crescimento das cidades intermediárias esteve atrelado a dois movimentos que se cruzaram: o de continuidade do processo de desconcentração produtiva regional e o de fortalecimento de um Estado que promove o gasto social. O primeiro tendeu a ser mais interiorizado, impulsionado pelo crescimento das exportações de bens primários (agrícolas, pecuários e minerais). O segundo colaborou para estimular a emancipação de municípios de mais baixa posição na hierarquia urbana nacional. Numa rede urbana verticalizada como a nordestina (centrada nas capitais de estado), os dois movimentos 
convergem mais claramente para uma reestruturação de relações espaciais ou para uma re-hierarquização do sistema urbano (emergência de novas centralidades) ${ }^{2}$.

Assim, por um lado, a continuidade das hierarquias exercidas pelo estrato superior da rede de cidades brasileira - como São Paulo, Rio de Janeiro e Brasília (IBGE, 2008) - demonstra o vigor das dinâmicas econômicas herdadas do período desenvolvimentista. Por outro, o processo combinado de interiorização/re-hierarquização projeta uma redefinição do padrão de urbanização nacional com maior crescimento urbano nas áreas não metropolitanas. O sentido é combinado porque se dá, num primeiro momento, com a saliência de núcleos urbanos de médio porte mais interiorizados e, num segundo, com o "extravasamento", ou melhor, com a influência direta do processo de metropolização na projeção de alguns núcleos ${ }^{3}$, modificando a dependência em relação às capitais de estado.

Do exposto, a hierarquia urbana brasileira, após 1990, passou por mudanças que refletem maiores heterogeneidades, complexidades e diversidades urbano-regionais. O ponto de inflexão não é exato, mas nasce do aumento da participação política (redemocratização) da sociedade brasileira e do redesenho federativo da Constituição Federal de 1988, marcando o processo de massificação das demandas socioespaciais (rurais, urbanas, regionais e territoriais) e o fortalecimento dos instrumentos do Estado em promover o gasto social, ainda que o desempenho efetivo dos entes federados deva ser considerado.

Estes últimos fatos colaboraram para estimular a emancipação de municípios de mais baixa posição na hierarquia urbana nacional, além do aumento considerável das cidades de porte médio e do avanço da fragmentação metropolitana. Conforme dados do IBGE, no ano de 2019, 57,4\% da população dos municípios com mais de 100 mil habitantes (ou 120,7 milhões de pessoas) concentrava-se em 324 municípios. Já os 48 municípios com mais de 500 mil habitantes concentravam 66,5 milhões de pessoas. $O$ tamanho da população é uma classificação válida para dar uma ideia do número das maiores nucleações, mas a distribuição das cidades de diferentes tamanhos no território nacional é assimétrica, pois sua hierarquia muitas vezes se limita à área de influência das cidades que concentram a produção e os serviços.

\footnotetext{
2. Santos (2009, p. 127) salienta que a hierarquia urbana é caracterizada, sobretudo, por uma "interdependência assimétrica” e funcional, haja vista que o sistema de cidades responde a ordens escalares diversas, nem sempre complementares entre si (local, regional, nacional e internacional). Ver: SANTOS, M. Por uma economia política da cidade. 2. ed. São Paulo: EDUSP, 2009.

3. Para uma clara distinção entre metrópole, região metropolitana e processo de metropolização, ver FIRKOWSKI (2013). FIRKOWSKI, O. L. C. F. Metrópoles e regiões metropolitanas no Brasil: conciliação ou divórcio. In: FURTADO, B. A. et al. (org.). Território metropolitano, políticas municipais: por soluções conjuntas de problemas urbanos no âmbito metropolitano. Brasília, DF: Ipea, 2013. p. 21-51.
} 
O Gráfico 1 permite observar a distribuição da população por período censitário, de acordo com a classe de tamanho, até 2010. Visualizam-se três momentos nessa evolução populacional: desde 1940-1950, quando predominam uma população dispersa e poucos núcleos com população acima de 500 mil habitantes, os quais representam pouco mais de $20 \%$ da população total; passando pelo auge da industrialização, no período 1950-1980, com destaque para a participação dos núcleos com mais de 500 mil habitantes representando mais de 30\% da população total; e o período pós-1980, com a ascensão dos chamados arranjos urbanos intermediários, ou seja, municípios que apresentam entre 100 mil e 500 mil habitantes, cuja participação na população total sai de pouco mais de $20 \%$ em 1980 para quase $30 \% \mathrm{em}$ 2010, quase se equiparando ao crescimento dos núcleos maiores.

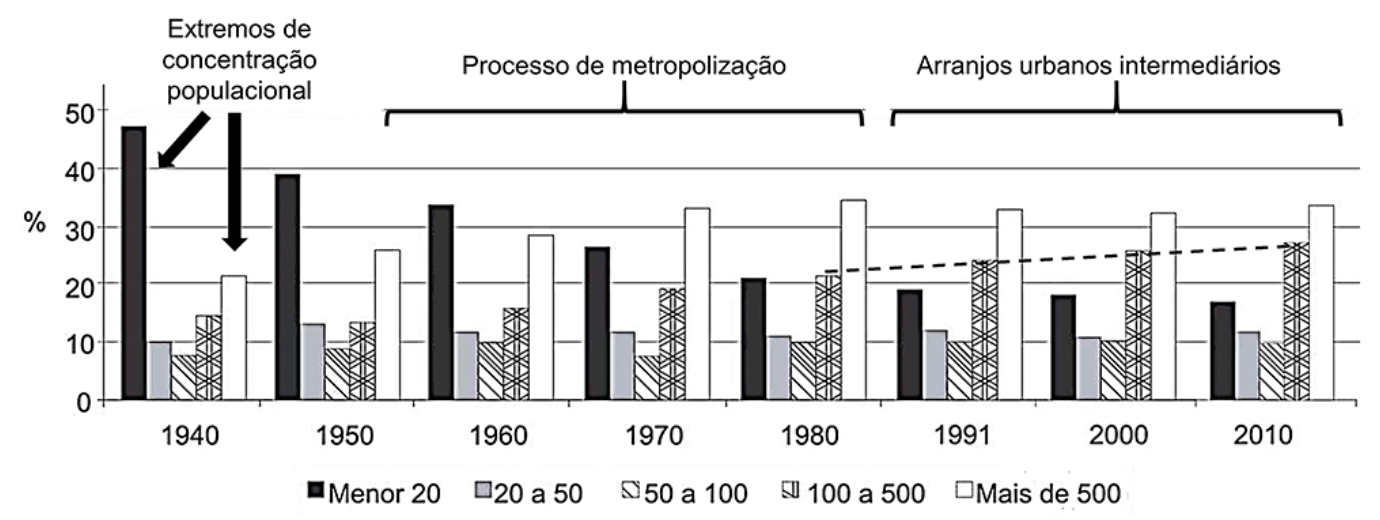

Gráfico 1. Distribuição da população urbana por classe de tamanho (1940-2010) Fonte: Elaborado pelos autores com base em STAMM et al. (2015).

Entretanto, a melhor distribuição alcançada pela concentração da população nos núcleos intermediários em âmbito nacional não ocorre regionalmente. No período posterior a 1980, os incrementos de populações urbanas são liderados por importantes nucleações das regiões Centro-Oeste, Nordeste e Norte (Gráfico 2), com diminuição relativa da participação das regiões Sudeste e Sul no período 1980-2010.

No caso do Nordeste, alta concentração da população vive nos maiores centros da região, acompanhando o processo verificado no país. São 34,5 milhões de pessoas vivendo nas cidades nordestinas, e cerca de vinte milhões delas habitam os maiores centros (IBGE, 2010). Isso sugere uma rede urbana assimétrica, comandada pelas capitais estaduais e apoiada por importantes centros urbanos dispersos no interior (IBGE, 2008).

Embora a distribuição dessa população continue dispersa em nucleações menores, as nucleações de porte médio ganharam destaque no período mais recente, 
pelos motivos já apontados. Essas nucleações mantêm relações mediadoras a jusante com as pequenas e a montante com as grandes cidades, quanto aos vínculos que criam e aos fluxos que portam. Contudo, pode-se dizer que, no caso nordestino, o amplo conjunto de cidades de pequeno e médio portes é tributário direto dos grandes centros (a montante). Logo, com menor intermediação dos mais importantes centros urbanos situados em seu interior, de forma a condicionar o dinamismo a sua economia.

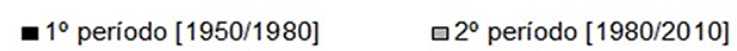

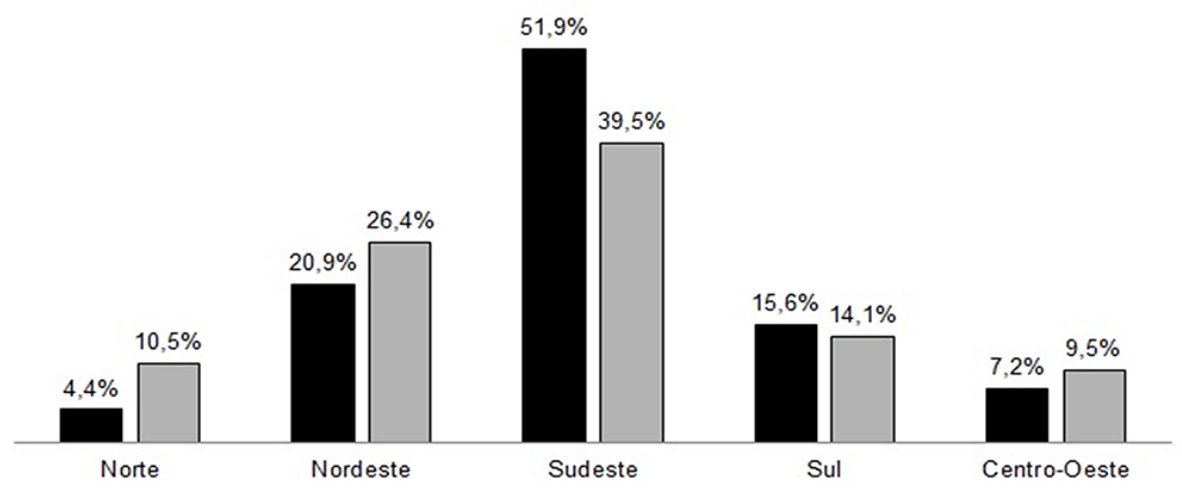

Gráfico 2. Brasil: incremento de população urbana por Grandes Regiões em dois períodos (população urbana Brasil $=100 \%$ )

Fonte: Elaborado pelos autores com base em STAMM et al. (2015).

Existe aí uma complexidade analítica de abarcar toda a rede em que tais cidades estão inseridas. Em áreas como as do interior da Bahia, as cidades médias tomadas de maneira isolada apresentam estrutura econômica com menor participação da administração pública na agregação de valor e menor proporção das transferências governamentais em seus orçamentos públicos. Porém, a dinâmica dessas cidades decorre de suas inserções no território como principais núcleos urbanos de vasta área dependente dos gastos governamentais, conforme discutido por Porto (2016).

Nesses casos, as interações entre as cidades - fluxo de pessoas e de mercadorias, equipamentos públicos e privados - não são ativadas apenas em função das decisões privadas do tipo capitalista. Antes, decorrem de ações político-administrativas do Estado e de políticas públicas, das quais resultam a localização dos serviços públicos, os investimentos em infraestrutura e os repasses e transferências de verbas, além das políticas sociais e dos instrumentos da seguridade, que ativam a renda de toda uma região. 
Com isso, o gasto público deve ser considerado um ativo relevante da concertação política que dá sentido ao pacto federativo em favor do desenvolvimento urbano-regional, algo que as políticas neoliberais insistem em destruir.

2. Transformações econômicas e a evolução do sistema de cidades na Bahia 2.1 Caracterização e condicionantes

Dado o contexto mais amplo, considera-se nesta seção a relação entre aquelas transformações e o desenvolvimento do sistema urbano da Bahia.

A Bahia está situada na região Nordeste do Brasil, com população estimada de 14,8 milhões de habitantes, para o ano de 2019, numa área de 564,7 mil km2. No ano de 2010, sua densidade demográfica era de 24,8 hab./km2, superando, na região Nordeste, apenas os estados do Maranhão e do Piauí. Em termos absolutos, apresentava a maior população rural do país, com pouco mais de 3,9 milhões de habitantes situados na zona rural (13,1\% da população rural do país). Além disso, cerca de dois terços do seu território e mais da metade dos seus municípios (266) estão situados na zona semiárida.

Embora sem o mesmo ritmo de transformações dos estados brasileiros de maior dinamismo econômico, o sistema urbano baiano modificou-se bastante desde o início do século XX. Houve especial aceleração a partir dos anos 1950, em face da intensificação do crescimento urbano-industrial vivenciado no país (SILVA; SILVA, 1989). Entre 1950 e 2010, o número de cidades da Bahia passou de 150 para 417, um aumento de $278 \%$. Já a população total do estado, que era de 4,8 milhões, chegou a 14,8 milhões de habitantes em 2019, segundo a última estimativa do IBGE.

A Bahia também refletiu o processo de transição de uma sociedade rural para outra mais urbana, cujo grau de urbanização passou de 25,9\% em 1950 para 72,1\% em 2010. Contudo, foi apenas em 1991 que o estado apresentou a predominância de população urbana em relação à rural. Sua concentração urbana é relativamente menor que a de estados da região Centro-Oeste e equivalente à dos estados da região Norte. A Bahia apresenta expressiva população rural vivendo na zona semiárida, com base econômica frágil ou limitada em termos dinâmicos, pelo menos de acordo com os padrões de crescimento anteriores.

Para a consolidação da dinâmica metropolitana soteropolitana, cabe relembrar qual foi o movimento da economia baiana em relação à nacional. Entre $1960 \mathrm{e}$ 1980, verificaram-se mudanças estruturais na indústria e no conjunto da economia baiana devidas ao crescimento das atividades petroquímica e metalúrgica. Com isso, a Bahia perdeu seu perfil agroexportador calcado na produção cacaueira, inserindo-se na matriz produtiva nacional, com a produção de bens intermediários (TEIXEIRA; GUERRA, 2000). 
Deu-se a implantação do Complexo Petroquímico de Camaçari (Copec), cuja consolidação permitiu ao setor industrial na Bahia quase triplicar sua participação no PIB do estado num intervalo de vinte anos. Com alta relação capital/trabalho, as empresas em operação e em implantação do Copec adentraram os anos 1990 numa relação de apenas três empregos diretos para cada milhão de dólares investidos (TEIXEIRA; GUERRA, 2000).

Para Alban (2005), o dinamismo econômico da fase desenvolvimentista perdurou na economia baiana até meados da década de 1980. Com a crise enfrentada pela economia nacional, aquele modelo teria se esgotado. A Bahia adotaria estratégias que visavam manter seu ritmo de crescimento semelhante ao do restante do país. Isso, porém, deveu-se a uma estrutura industrial mais integrada ao núcleo dinâmico brasileiro, passando a apresentar as mesmas oscilações.

Resultam dessa discussão alguns dos principais condicionantes do atual sistema urbano baiano. Preservou-se forte inércia vinculada aos domínios territoriais de ocupação mais antiga, refletindo as condições do subdesenvolvimento ou a "permanência do atraso". Abriram-se novas frentes de expansão tanto em direção ao sul e ao extremo sul do estado como em direção ao oeste. Por fim, consolidou-se um polo industrial com relativo dinamismo no litoral do Recôncavo. A combinação desses fatores condicionantes caracteriza a atual influência do processo de metropolização. Os rebatimentos dessas transformações sobre o conjunto de cidades da Bahia poderão ser verificados nas subseções seguintes.

\subsection{As cidades baianas e a configuração de sua rede urbana}

A estruturação do sistema urbano na Bahia guarda características regionais específicas, as quais se referem ao processo histórico de formação das diferentes regiões de um país continental como o Brasil e à forma como cada região se inseria na divisão interna do trabalho, à medida que se efetivavam o processo de industrialização e a integração do mercado nacional. Podemos dizer que a Bahia se caracterizou pela constituição de um sistema de cidades verticalizado, com dinâmica econômica e populacional concentrada em poucos municípios. Isso também se reflete na maior importância do setor público nas dinâmicas urbana e econômica municipais.

O sistema urbano, assim como a urbanização, sintetiza longos processos de transformações territoriais do país, cujas dinâmicas econômicas têm "forte papel indutor" (IPEA; IBGE; UNICAMP, 2001, p. 33). Um sistema urbano se constitui na junção das cidades e de suas áreas de influência (IBGE, 2008; 2020), com base em critérios de contiguidade espacial e de relações funcionais entre elas. O conjunto de diversos sistemas urbano-regionais conforma a rede urbana brasileira, que ex- 
pressa o modo como as cidades articulam fluxos sociais e econômicos pelo território nacional (IPEA; IBGE; UNICAMP, 2001; CORRÊA, 2006).

Com isso, é importante perceber como foi se estruturando o sistema urbano baiano. Em 1950, 81,3\% das cidades do estado tinham menos de 5 mil habitantes. No ano de 1980, esse número caiu para 61,6\% e, em 2010, a proporção era de apenas 31,6\%. Um dos motivos substanciais dessa queda está na redução da criação de novos municípios após a Constituição Federal de 1988. Quando se observam as sedes municipais com população superior a 20 mil habitantes, apenas seis cidades (4\%) se enquadravam nessa classificação em 1950. A cifra subiu para 8,9\% no ano de 1980 (trinta cidades) e para 15,1\%, em 2010, o que equivale a 63 cidades.

A cidade de Salvador respondia por 8,6\% da população baiana em 1950, vindo a aumentar sistematicamente sua participação e fechando o ano de 2010 com 19,1\%. A partir dos anos 1950, a centralidade da capital foi cada vez mais reforçada com o advento da Petrobras e as práticas estatais de planejamento econômico. Tiveram forte influência sobre o processo de urbanização soteropolitana os investimentos industriais no Centro Industrial de Aratu (CIA), na década de 1960, e no Copec, nos anos 1970. Também contribuíram as transferências federais e os investimentos estatais e privados em ramos não industriais, como serviços e turismo.

\begin{tabular}{l|c|c|c|c|c|c|c|c|c}
\hline \multirow{2}{*}{$\begin{array}{l}\text { Classes de tamanho } \\
\text { dos municípios }\end{array}$} & \multicolumn{3}{|c|}{ Quantidade } & \multicolumn{3}{c|}{$\begin{array}{c}\text { Participação da } \\
\text { população total (\%) }\end{array}$} & \multicolumn{3}{c}{$\begin{array}{c}\text { Grau de } \\
\text { urbanização (\%) }\end{array}$} \\
\cline { 2 - 12 } & 1991 & $\mathbf{2 0 0 0}$ & $\mathbf{2 0 1 0}$ & 1991 & $\mathbf{2 0 0 0}$ & $\mathbf{2 0 1 0}$ & $\mathbf{1 9 9 1}$ & $\mathbf{2 0 0 0}$ & $\mathbf{2 0 1 0}$ \\
\hline Até 10 mil & 74 & 70 & 69 & 4,8 & 4,0 & 3,6 & 37,4 & 46,4 & 52,6 \\
\hline Entre 10 mil e 50 mil & 308 & 307 & 305 & 51,3 & 47,6 & 44,1 & 39,6 & 48,1 & 53,3 \\
\hline Entre 50 mil e 100 mil & 24 & 26 & 27 & 13,4 & 13,5 & 12,6 & 65,1 & 69,5 & 71,0 \\
\hline Entre 100 mil e 200 mil & 5 & 8 & 11 & 5,8 & 8,9 & 11,2 & 87,7 & 89,9 & 88,8 \\
\hline Entre 200 mil e 500 mil & 3 & 3 & 3 & 7,2 & 7,4 & 5,4 & 79,8 & 84,9 & 93,6 \\
\hline Entre 500 mil e 1 milhão & 0 & 0 & 1 & - & - & 4,0 & 0,0 & 0,0 & 91,7 \\
\hline Mais de 1 milhão & 1 & 1 & 1 & 17,5 & 18,7 & 19,1 & 99,9 & 100,0 & 100,0 \\
\hline Total & 415 & 415 & 417 & 100,0 & 100,0 & 100,0 & 59,1 & 67,0 & 72,1 \\
\hline
\end{tabular}

Tabela 1. Bahia: número de municípios, grau de urbanização e participação no total da população, segundo as classes de tamanho dos municípios (1991-2010)

Fonte: IBGE. Censos Demográficos, 1991-2010. Banco de Dados Agregados - Sistema IBGE de Recuperação Automática (SIDRA).

Já no interior do estado, denota-se a má distribuição do seu conjunto de cidades, tanto em termos geográficos como em relação ao tamanho. Formaram-se núcleos dinâmicos, em termos populacionais e econômicos, nas regiões limítrofes da Bahia. Tem destaque o adensamento nas cidades litorâneas, como Ilhéus e Ita- 
buna, e naquelas próximas à RMS, além de Barreiras, no oeste do estado; Juazeiro, ao norte; Feira de Santana, Jequié e Vitória da Conquista, ao longo da BR-116.

$\mathrm{Na}$ Tabela $1^{4}$, verifica-se que os municípios com até 10 mil habitantes e entre 10 mil e 50 mil habitantes, juntos, correspondiam, em 1991, a 92\% dos municípios baianos. Nesses grupos, vivia $56,1 \%$ da população do estado. No ano 2000, os percentuais alteraram-se para 90,1\% e 51,6\%, respectivamente. Já em 2010, 89,7\% dos municípios baianos tinham menos de 50 mil habitantes, com $47,7 \%$ da população do estado.

Durante esse período, houve perda de participação relativa desses grupos no total do estado. Isso se deveu principalmente ao fato de os municípios perderem parte de sua população, movidos ainda pelos fatores históricos de expulsão. Mas, também, pelo maior crescimento populacional das cidades baianas de maior porte.

Destaca-se o grupo situado entre 100 mil e 200 mil habitantes, pois apresenta o maior crescimento do período. Entre 1991 e 2010, a taxa média de crescimento populacional foi de $4,4 \%$ a.a. - crescimento de $68,7 \%$ entre 1991 e 2000 e de $34,9 \%$ entre 2000 e 2010 -, saltando de cinco para onze municípios. Em ordem crescente de população, em 2010, foram eles: Eunápolis (100.196 habitantes), Paulo Afonso (108.396), Simões Filho (118.047), Porto Seguro (126.929), Barreiras (137.427), Teixeira de Freitas (138.341), Alagoinhas (141.949), Jequié (151.895), Lauro de Freitas (163.449), Ilhéus (184.236) e Juazeiro (197.965). Nesse grupo, o grau médio de urbanização alcançou 88,8\%, em 2010, quando era de 89,9\% em 2000, cuja redução se deveu à incorporação de novos municípios.

Por fim, nos grupos situados entre 200 mil e 1 milhão de habitantes encontramos quatro municípios alternando a participação nessas classes de tamanho. Entre 1991 e 2000, os municípios de Feira de Santana, Vitória da Conquista e Ilhéus situavam-se na faixa entre 200 mil e 500 mil habitantes. Já em 2010, Feira de Santana figurava no grupo superior a 500 mil habitantes, enquanto Vitória da Conquista, Itabuna e Camaçari se mantinham no grupo intermediário, entre 200 mil e 500 mil habitantes.

Destaca-se o crescimento populacional do município de Camaçari, situado na RMS e, portanto, com dinâmica diferenciada das demais cidades do grupo, localizadas no interior. Seu desempenho foi influenciado pelo aumento do número de condomínios fechados, recebendo população da capital, além do fato de lá se situarem as principais fábricas do Projeto Amazon (Ford), instalado no início dos anos 2000 (DIAS; ARAÚJO, 2013).

4. A partir de 1991 emanciparam-se apenas dois municípios, o que torna a base de comparação mais confiável. 
O sistema urbano que se consolidou na Bahia apresenta uma rede dispersa de cidades, com relativo adensamento econômico e populacional no litoral e RMS e um pouco numeroso e mal distribuído conjunto de cidades de porte médio no interior do estado. Reflete com diferentes intensidades o processo de urbanização brasileira, isto é, a lógica urbana de reprodução da sociedade, própria do avanço das relações capitalistas de produção do tipo de desenvolvimento que se deu no Brasil, o que ficará mais claro a seguir.

\section{Região de Influência de Salvador (RIS) e os (sub)sistemas urbanos do interior}

Na RMS 5 , concentra-se a maior parte da riqueza material da Bahia, com destaque para os serviços e o aparelho administrativo do estado. Composta de treze municípios, a RMS correspondia, em 2010, a 25\% da população baiana, elevando a sua participação em relação ao ano de 2000 (23\%). O conhecimento da estruturação da rede de cidades que é articulada a partir da RMS nos permite fazer algumas considerações a respeito de sua importância e da dimensão (econômica e demográfica) de sua área de influência. Além disso, chamamos a atenção para o caráter dinâmico da rede urbana, cujos recortes territoriais político-administrativos dificilmente dão conta de representar.

Nesse caso, a caracterização do que chamaremos de Região de Influência de Salvador (RIS) busca refletir o "protagonismo da geografia traçada pelos fluxos socioeconômicos no processo contínuo de estruturação do território nacional” (IBGE, 2008, p. 5). Também expõe o comando dessa metrópole sobre uma significativa porção do território, dado pela força alcançada em seu espaço de atuação urbano-regional.

Noutro aspecto, a utilização da RIS viabiliza novos recortes espaciais para a pesquisa acadêmica que não se prendem às divisas do estado ou às regionalizações administrativas estaduais. A RIS objetiva combinar o processo de urbanização e integração do mercado nacional com o surgimento de estruturas verticais dentro da rede urbana brasileira, que fortalecem as cidades como elementos fundamentais de centralidade urbana (IBGE, 2013).

Para verificar o grau de abrangência da RIS, utilizamos as informações da publicação Divisão urbano-regional, do IBGE (2013), que delimita as regiões de maior influência das principais cidades do Brasil. Essa divisão consiste em "espa-

5. A RMS foi instituída em junho de 1973 e é composta, atualmente, dos municípios de Camaçari, Candeias, Dias d’Ávila, Itaparica, Lauro de Freitas, Madre de Deus, Mata de São João, Pojuca, Salvador, São Francisco do Conde, São Sebastião do Passé, Simões Filho e Vera Cruz. 
ços pautados numa organização em rede, onde os centros de gestão do território determinam as vinculações e o arranjo regional” (IBGE, 2013, p. 3).

Na Figura 1, destaca-se a abrangência da RIS e seus principais centros urbanos, que abarca a quase totalidade do território baiano e do estado de Sergipe, além de alguns municípios situados nos estados de Minas Gerais, Pernambuco e Alagoas. A exceção é a área ao sul da Bahia, que, conforme o IBGE (2008), apresenta um conjunto maior de articulações com a rede urbana do Espírito Santo ${ }^{6}$.

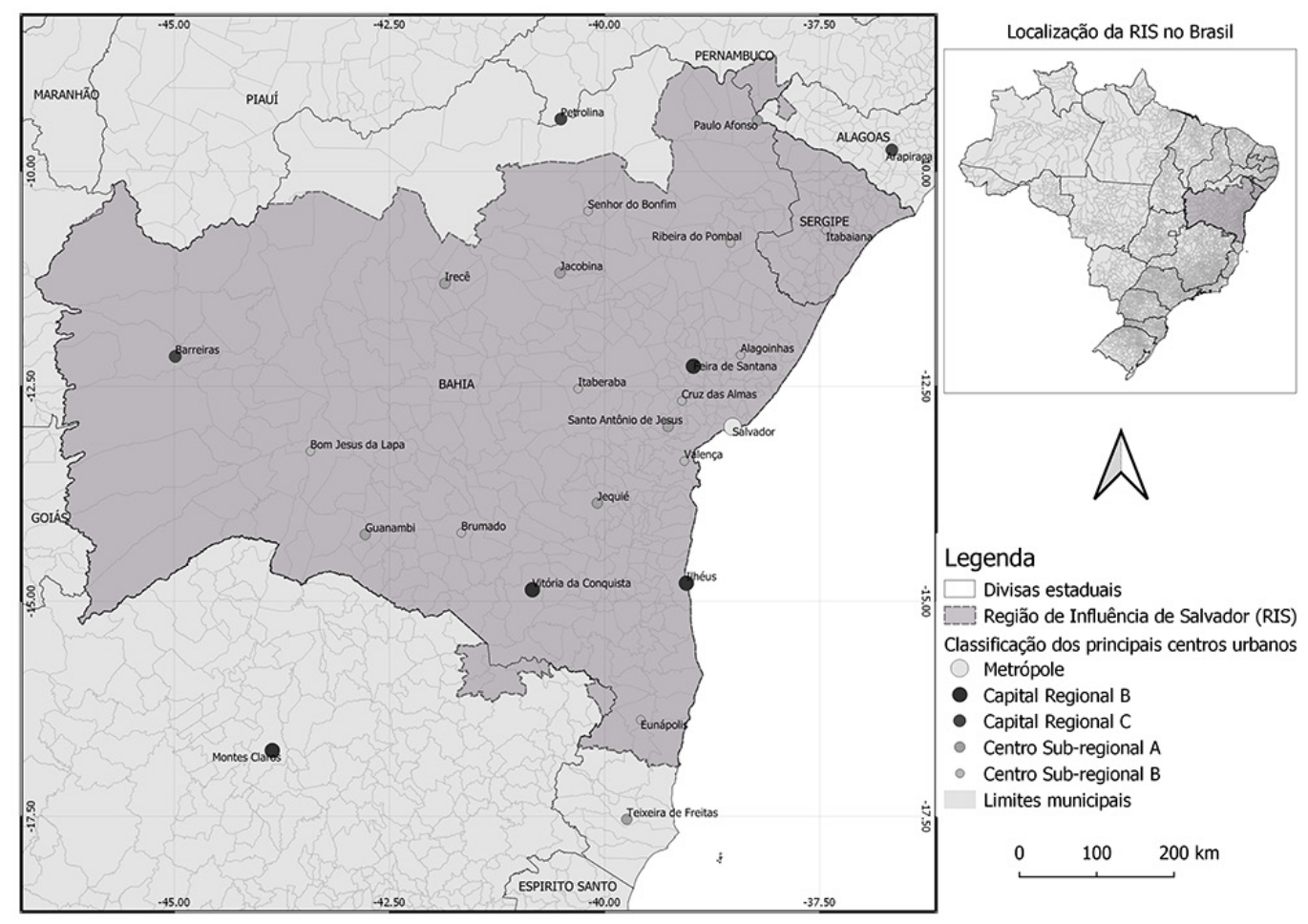

Figura 1. Região de Influência de Salvador (RIS) e principais núcleos urbanos, segundo os níveis de hierarquia

Fonte: IBGE, Malhas digitais, 2015; Regic, 2007; Divisão urbano-regional do Brasil (IBGE, 2013).

A RIS compõe-se de 480 municípios, numa área de 516,8 mil km2 (6,1\% do território nacional) e uma população de 15,3 milhões de pessoas, em 2010, com densidade demográfica de $29,7 \mathrm{hab} . / \mathrm{km} 2$. Sua população corresponde a $8 \%$ do total do país e a $109 \%$ do total da Bahia, uma vez que extrapola as divisas feitas por esse estado. Em 2015, seu PIB foi de R 272,7 bilhões, em torno de 4,5\% do PIB nacional. No mesmo ano, a agropecuária representava 7,5\% do Valor Adicionado Bruto

6. Esse dado se confirma com a nova Regic (IBGE, 2020), que elevou a aglomeração urbana de Vitória, no Espírito Santo, à categoria de metrópole, evidenciando sua influência sobre aquela porção do estado da Bahia. 
(VAB) da região, enquanto a indústria respondia por 22,3\%. Já o setor de serviços, desagregado dos serviços de administração pública (APU), correspondia a 48,7\%, e a APU, a $21,4 \%$.

A conformação espacial da RIS se assemelha àquela com que os movimentos históricos foram constituindo aquela região. A delimitação de sua área se aproxima da antiga região Leste, composta dos estados de Bahia e Sergipe, antes da atual divisão do país em cinco macrorregiões. Araújo (2000) já havia se referido a esse subespaço do Nordeste comandado por Salvador e sob a hegemonia de uma burguesia banqueira. Para essa autora, ali se conformaram subáreas onde se verifica a predominância da cana-de-açúcar, do cacau, assim como subáreas do sertão semiárido e da porção oeste do estado da Bahia, sendo esta última parte do cerrado nordestino, outrora "vazia”, mas progressivamente transformada pelo agronegócio.

Os níveis de hierarquia dos centros urbanos vinculados à RIS decorrem da Regic-2007 (IBGE, 2008), evidenciando os poucos centros urbanos de médio e grande portes situados nos níveis intermediários. Com isso, os núcleos urbanos pertencentes à RIS foram agrupados da seguinte maneira:

- Metrópole: aglomeração urbana com doze municípios da RMS7, tendo Salvador como o núcleo principal e população total de 3,5 milhões de pessoas (23\% da RIS), com grau de urbanização de 98,1\%, em 2010. Em 2015, concentrava 39\% do PIB da região, com a indústria respondendo por $30 \%$ de seu VAB e os serviços, por $57 \%$.

- Capitais Regionais: são cinco aglomerações urbanas, num total de onze municípios, dos quais seis pertencem à Área de Concentração Populacional (ACP) de Aracaju-SE (Capital Regional A), dois à ACP de Ilhéus-Itabuna, além de Vitória da Conquista, Feira de Santana (Capital Regional B) e Barreiras (Capital Regional C). Juntos, representavam 15\% da população da RIS, em 2010, e 18\% do PIB da região, no ano de 2015.

- Centros Sub-regionais: são dezesseis cidades, das quais seis Centros Sub-regionais A e dez Centros Sub-regionais B. Respondiam por 9\% da população total da RIS, em 2010, e por 8\% do PIB, em 2015. Em média, o grau de urbanização, no ano de 2010, era de 82\%.

- Centros de Zona: 39 municípios, dos quais quinze são Centro de Zona A e o restante, Centro de Zona B. Em 2010, apresentaram grau de urbanização médio de $66 \%$, com $10 \%$ da população total da RIS e $7 \%$ do PIB.

- Centros Locais: os 402 núcleos restantes que pertencem a este grupo respondiam por $43 \%$ da população da RIS, com grau de urbanização médio

7. A exceção é o município de Pojuca (BA), que aparece como Centro local na Regic-2007. 
de $51 \%$ no ano de 2010. Em contraste, representavam apenas $27 \%$ do PIB da região, com destaque para o peso da APU no VAB total, de 32\% em 2015.

\begin{tabular}{|c|c|c|c|}
\hline \multirow{2}{*}{ Produto Interno Bruto, Impostos e Valor Adicionado } & \multicolumn{3}{|c|}{ Participação relativa (\%) } \\
\hline & 1999 & 2005 & 2012 \\
\hline \multicolumn{4}{|l|}{ Produto Interno Bruto } \\
\hline$\% \mathrm{RMS} / \mathrm{BR}$ & 2,12 & 2,21 & 1,66 \\
\hline$\%$ RMS/RIS & 49,03 & 47,13 & 38,73 \\
\hline$\%$ RIS/BR & 4,33 & 4,69 & 4,29 \\
\hline$\%$ SSA/RMS & 53,69 & 47,50 & 54,66 \\
\hline \multicolumn{4}{|l|}{ Impostos } \\
\hline$\% \mathrm{RMS} / \mathrm{BR}$ & 2,49 & 2,90 & 2,10 \\
\hline$\%$ RMS/RIS & 64,63 & 64,04 & 55,75 \\
\hline$\%$ RIS/BR & 3,85 & 4,52 & 3,76 \\
\hline$\%$ SSA/RMS & 49,73 & 44,98 & 49,93 \\
\hline \multicolumn{4}{|l|}{ VA agropecuária } \\
\hline$\%$ RMS/BR & 0,12 & 0,07 & 0,06 \\
\hline$\%$ RMS/RIS & 2,26 & 1,19 & 1,12 \\
\hline$\%$ RIS/BR & 5,21 & 6,12 & 5,26 \\
\hline$\%$ SSA/RMS & 6,82 & 15,14 & 14,82 \\
\hline \multicolumn{4}{|l|}{ VA indústria } \\
\hline$\%$ RMS/BR & 2,73 & 3,14 & 1,77 \\
\hline$\%$ RMS/RIS & 59,06 & 59,28 & 39,80 \\
\hline$\%$ RIS/BR & 4,62 & 5,29 & 4,44 \\
\hline$\%$ SSA/RMS & 30,76 & 22,95 & 31,37 \\
\hline \multicolumn{4}{|l|}{ VA serviços (s/ administração pública) } \\
\hline$\% \mathrm{RMS} / \mathrm{BR}$ & 2,24 & 2,01 & 1,82 \\
\hline$\%$ RMS/RIS & 54,73 & 49,28 & 45,56 \\
\hline$\%$ RIS/BR & 4,09 & 4,07 & 3,99 \\
\hline$\%$ SSA/RMS & 66,36 & 67,55 & 66,08 \\
\hline \multicolumn{4}{|l|}{ VA administração pública } \\
\hline$\% \mathrm{RMS} / \mathrm{BR}$ & 1,04 & 1,13 & 1,05 \\
\hline$\%$ RMS/RIS & 21,65 & 21,75 & 19,93 \\
\hline$\%$ RIS/BR & 4,79 & 5,19 & 5,25 \\
\hline$\%$ SSA/RMS & 71,70 & 69,65 & 65,02 \\
\hline
\end{tabular}

Tabela 2. RMS: participação relativa no PIB e VAB dos setores de atividade econômica no Brasil e na RIS (1999-2012)

Fonte: IBGE/Produto Interno Bruto dos Municípios (1999-2012). Banco de Dados Agregados - Sistema IBGE de Recuperação Automática (SIDRA). 
Com os dados da Tabela 2, fazemos algumas considerações a respeito da dinâmica econômica da RMS e da RIS. A RMS contribuiu com 1,7\% da atividade econômica do país em 2012. Comparada à RIS, sua participação foi de $38,7 \%$, revelando a importância da metrópole sobre o conjunto de cidades atendido por ela. Porém, houve redução da sua participação relativa na região, que era de 49,0\%, em 1999. A maior perda da RMS em relação à RIS deve-se ao VAB da Indústria, cuja redução entre o ano de 2005 e 2012, apenas sete anos, foi de quase 20 p.p. (de 59,3\% para 39,8\%).

Os dados apontam certa desconcentração econômica dentro da RIS e, por conseguinte, do estado da Bahia. Todavia, também se verifica a elevação da participação do núcleo da metrópole no VAB da indústria pela RMS de 22,9\% para 31,4\%. Isso pode estar relacionado com a queda de dinamismo da indústria baiana, tal como vem acontecendo com a indústria nacional (CANO, 2008), repercutindo no enfraquecimento de segmentos industriais situados na região metropolitana.

Ganha destaque o peso do setor de Serviços (exceto administração pública) da RMS sobre sua área de influência. Com $45,6 \%$ de todo o valor adicionado dos serviços pela RIS, em 2012, verifica-se o papel de comando exercido pela metrópole. Chama-se a atenção para o peso que a RIS tem sobre o PIB do país. Com contribuição de apenas 4,3\% do PIB nacional, trata-se de uma região de dinamismo econômico concentrado, já que mais de um terço desse valor é gerado pela região metropolitana.

Esse quadro permite tecer algumas reflexões sobre as redes urbanas secundárias no território baiano. A Bahia possui amplo território com razoável densidade populacional. Não obstante, a distribuição do tamanho populacional de suas cidades aponta para o reduzido número de cidades de porte médio. Por isso, assume-se que o deslocamento populacional e os fluxos econômicos se direcionam para poucos destinos dentro do estado da Bahia.

Há uma rede principal de cidades baianas que concentra os fluxos sociais e econômicos do seu território. Tais cidades atuam como entreposto desses fluxos entre os distintos lugares de sua área de influência e de outras regiões (PORTO, 2003).

Silva e Silva (2006) demonstraram que as microrregiões mais dinâmicas do estado tendem a reproduzir, em escalas menores, a mesma tendência estadual e nacional, no que tange aos desequilíbrios socioeconômicos existentes em seu interior. Os autores argumentam ser necessário fortalecer as cidades médias no interior da Bahia, desempenhando o papel de capitais regionais.

O estudo Quatro cantos da Bahia, feito pela Secretaria de Planejamento desse estado, procurou identificar e caracterizar os espaços da produção em seu terri- 
tório, utilizando indicadores sobre o porte de comércio e de serviços das cidades baianas $^{8}$ (BAHIA, 2001). Seus resultados apontaram que,

[...] abstraindo alguns desvios localizados, no geral são as mesmas cidades que se enquadram nos três indicadores considerados e são aqueles que servem como centralidade das manchas de produção industrial. [...] também são estas localidades que estão presentes nos locais onde há uma superposição de fluxos dos setores primário e secundário, estando nestas próprias cidades as maiores concentrações das atividades terciárias (BAHIA, 2001, p. 61).

Essas cidades exercem o papel de centros de apoio às atividades de serviços, comércio, educação, saúde etc. e dão suporte à circulação das mercadorias no espaço nacional. Avalia-se, no entanto, que há concentração dos fluxos de suas áreas de influência dentro do próprio estado. O papel de rede secundária de entreposto comercial entre estados é exercido por cidades como Vitória da Conquista, Jequié e Feira de Santana. Também aparecem as cidades de pequeno porte dispersas no território, motivadas pelo surgimento de novas rotas de fluxos comerciais, demandando pouca infraestrutura urbana (PORTO, 2003).

Dias e Araújo (2013), por seu turno, buscaram esboçar uma tipologia própria para as cidades médias baianas. Apontaram um total de 32, cuja população oscila entre 40 mil e 500 mil habitantes, não localizadas na RMS. Essas cidades apresentam a condição de Capital Regional ou Centro Sub-regional na metodologia da Regic. Porém, a disposição delas no território baiano denota a ausência de cidades médias na porção semiárida, o que dificulta um melhor entendimento de suas articulações interurbanas.

Como demonstrado, o quadro que ora se apresenta vem sendo discutido por diversos pesquisadores. Nota-se que, embora a discussão seja tecida com base em diferentes pontos de vista, esses autores se ativeram ao mesmo fenômeno, com resultados semelhantes. Isto é, o conjunto de cidades principais da Bahia é sempre o mesmo. Isso requer que sejam feitas observações adicionais, apontando para alguns condicionantes às articulações existentes entre as principais cidades do estado. São elas:

- As nuances em seu desenvolvimento econômico, tais como: i) as relações mais intensas com o Centro-Sul do país; ii) a presença do cacau e outras culturas diferentes do binômio pecuária-algodão que caracterizou a economia nordestina no passado;

8. Foram eles: a) o volume de capital-moeda, medido pelos depósitos bancários; b) o consumo de energia elétrica nos estabelecimentos comerciais e de serviços; e c) o contingente populacional (BAHIA, 2001). 
- A extração do petróleo e a fase áurea da industrialização brasileira, com o reforço do (sub)sistema urbano do Recôncavo e a mudança da economia baiana, além do processo de metropolização e o peso crescente da RMS;

- As novas atividades econômicas que permitem qualificar o desenvolvimento de cidades em algumas regiões do estado: a produção de grãos no oeste, o papel e celulose no sul e extremo sul, a fruticultura irrigada ao norte, o turismo e a extração de minérios em diversos pontos do território baiano;

- Em oposição, temos a região semiárida, cuja formação histórica mais se aproxima do binômio pecuária-algodão, despontando algumas importantes cidades de porte médio que exercem centralidades isoladas, como é o caso de Vitória da Conquista (PORTO, 2016), onde se destaca a forte dependência da economia do setor público em sua área de influência;

- A viabilização de projetos pontuais via "guerra fiscal", como o Projeto Amazon, na RMS, o Polo de Informática de Ilhéus e a indústria calçadista em Jequié e em Itapetinga, no interior do estado

Nota-se que, à medida que adquirem novas centralidades, as cidades principais passam a ser atrativas a novos segmentos sociais. Porém, esse ganho de centralidade não as capacita de fato como áreas dinamizadoras do desenvolvimento baiano. Nem poderiam, pois estão situadas em espaços que reforçam o quadro de heterogeneidade e das desigualdades regionais. Sobretudo, porque funcionam mais como canais pelos quais a (pequena) riqueza regional é drenada até níveis superiores da rede urbana do que como centros irradiadores do desenvolvimento.

Nesse sentido, reconhecemos que as funções de intermediação desse conjunto de cidades estão condicionadas às respectivas estruturas econômicas e sociais das áreas onde estão situadas. Portanto, ou estaríamos tratando de tipos regionalmente específicos de cidades médias ou existem poucas cidades com funções reais de intermediação dentro do estado da Bahia.

Esta última opção é a que vem se mostrando mais plausível. Isso nos leva a considerar que as redes de cidades baianas traduzem maiores verticalidades. Por essa razão, apresentam (poucos) núcleos urbanos que centralizam áreas e populações relativamente extensas e com menor diferenciação na divisão regional do trabalho, fato que torna premente pensar o sentido de uma regionalização mais dinâmica voltada ao interior do estado.

\section{Considerações finais}

Ao longo do texto, procuramos discutir alguns dos principais condicionantes à atual configuração do sistema de cidades do estado da Bahia. Propôs-se uma reflexão sobre como o território baiano e suas cidades foram se inserindo na divisão 
espacial do trabalho brasileira. Para tanto, passou-se a discutir as características atuais desse sistema de cidades.

Podemos dizer que o sistema urbano baiano se caracterizou pela constituição de uma rede urbana com dinâmica econômica e populacional concentrada em poucos centros urbanos. Isso também se reflete na maior dependência que os municípios de menor porte têm do setor público em suas dinâmicas urbana e econômica, fator que se manifesta com o elevado peso que ele assume nos municípios presentes na base da hierarquia urbana regional (centros locais).

Nos núcleos urbanos de maior porte, o estado concentra o papel de centralizar áreas e populações relativamente extensas, com pouca ou nenhuma diferenciação na divisão regional do trabalho, com reflexos tanto dentro da rede urbana, em sua dimensão nacional e estadual, como nas respectivas áreas de influência, revelando-se maior número de vínculos externos às suas regiões.

Por fim, verificou-se a caracterização atual da rede de cidades que é articulada a partir da RMS, configurando um espaço urbano-regional que extrapola as divisas feitas pela Bahia. Assim, a RIS abarca a quase totalidade do território baiano e de Sergipe, além de algumas municipalidades de outros estados da federação. A análise da RIS permitiu indicar alguns aspectos do padrão que caracteriza o sistema urbano baiano e, nesse sentido, apontou para alguns condicionantes às articulações existentes entre as principais cidades desse estado, cujas condições estruturais reclamam por soluções próprias.

\section{Referências}

ALBAN, M. O novo enigma baiano, a questão urbano-regional e a alternativa de uma nova capital. In: ENCONTRO NACIONAL DA ASSOCIAÇÃO NACIONAL DE PÓS-GRADUAÇÃO E PESQUISA EM PLANEJAMENTO URBANO E REGIONAL, XI, 2005, Salvador. Anais [...] Salvador: Universidade Federal da Bahia, 2005.

ARAÚJO, T. B. Nordeste, nordestes: que Nordeste? In: Ensaios sobre o desenvolvimento brasileiro: heranças e urgências. Rio de Janeiro: Revan, 2000.

BAHIA. Secretaria do Planejamento, Ciência e Tecnologia. Superintendência de Planejamento Estratégico. Quatro cantos da Bahia. Salvador: Superintendência de Planejamento Estratégico, 2001. 109p.

BRANDÃO, C. Transformar a provisão de bens e serviços públicos e coletivos nos espaços urbanos e regionais do Brasil. Revista eMetropolis, ano 6, n. 23, p. 6-13, dez. 2015.

CANO, W. Soberania e política econômica na América Latina. São Paulo: Ed. Unesp; Campinas: Unicamp-Economia, 2000.

Desconcentração produtiva regional no Brasil 1970/2005. 3. ed. São Paulo: Ed. Unesp, 2008. 
CANO, W. Novas determinações sobre as questões regional e urbana após 1980. Revista brasileira de estudos urbanos e regionais, v. 13, n. 2, p. 27-53, 2011.

CORREAA, R. L. Estudos sobre a rede urbana. Rio de Janeiro: Bertrand Brasil, 2006.

DIAS, P. C.; ARAÚJO, M. M. S. Notas sobre cidades médias: uma proposta para a Bahia. Geo UERJ, v. 1, p. 285-311, 2013. ISSN 1981-9021.

INSTITUTO BRASILEIRO DE GEOGRAFIA E ESTATÍSTICA (IBGE). Regiões de influência das cidades: 2007. Rio de Janeiro: IBGE, 2008.

Divisão urbano-regional do Brasil. Rio de Janeiro: IBGE - Divisão de Geociência, 2013.

. Regiões de influência das cidades: 2018. Rio de Janeiro: IBGE, 2020.

INSTITUTO DE PESQUISA ECONÔMICA APLICADA (IPEA); INSTITUTO BRASILEIRO DE GEOGRAFIA E ESTATÍSTICA (IBGE); INSTITUTO DE PESQUISA ECONÔMICA APLICADA; INSTITUTO BRASILEIRO DE GEOGRAFIA E ESTATÍSTICA; UNIVERSIDADE ESTADUAL DE CAMPINAS (UNICAMP). Configuração atual e tendências da rede urbana. Brasília, DF: Ipea, 2001. 396p. (Caracterização e tendências da rede urbana do Brasil, 1).

LAVINAS, L. América Latina: mínimos monetários em lugar da proteção social. Revista Política Social e Desenvolvimento, ano 2, n. 8, p. 18-27, nov. 2014.

MACEDO, F. C.; MORAIS, J. M. L. Inserção comercial externa e dinâmica territorial no Brasil: especialização regressiva e desconcentração produtiva regional. Informe Gepec, v. 15, n. 3, p. 82-98, 2011.

ORAIR, R. O. Dilemas do financiamento das políticas públicas nos municípios brasileiros: uma visão geral. In: COSTA, M. A. O Estatuto da Cidade e a Habitat III: um balanço de quinze anos da política urbana no Brasil e a nova agenda urbana. Brasília, DF: Ipea, 2016. cap. 9, p. 233-264.

PORTO, E. Desenvolvimento e território na Bahia. Salvador: Superintendência de Estudos Econômicos e Sociais da Bahia, 2003. (Série Estudos e Pesquisas, 61).

PORTO, L. R. Urbanização e dinâmica econômica da rede urbana no estado da Bahia (19402010): o caso de Vitória da Conquista (BA). 2016. 164f. Dissertação (Mestrado) -Instituto de Economia, Universidade Estadual de Campinas, Campinas, 2016.

QUADROS, W. Melhorias sociais no período 2004 a 2008. Campinas: IE-Unicamp, 2010. (Texto para discussão, n. 176).

. 2009 a 2012: heterodoxia impulsiona melhorias sociais. Campinas: IE-Unicamp, 2014. (Texto para discussão, n. 230).

SANTOS, M. Guerra dos lugares. São Paulo: Folha de S.Paulo, 1999. p. 3.

. A urbanização brasileira. 5. ed. São Paulo: EDUSP, 2005 [1993].

SILVA, S. C. B. M.; SILVA, B. C. N. Dinâmica recente do processo de urbanização/metropolização 1931/1985. In: SILVA, S. C. B. M.; LEÃO, S. O.; SILVA, B. C. N. Urbanização e metropolização no estado da Bahia: evolução e dinâmica. Salvador: Universidade Federal da Bahia, 1989. p. 187-262. 
SILVA, S. C. B. M.; SILVA, B. C. N. Desequilíbrios regionais e municipais no estado da Bahia. In: SUPERINTENDÊNCIA DE ESTUDOS ECONÔMICOS E SOCIAIS DA BAHIA. Desenvolvimento regional: análises do Nordeste e da Bahia. Salvador: SEI, 2006, v. 3, n. 30, p. 95-111. (Série Estudos e Pesquisas, 73).

TEIXEIRA, F.; GUERRA, O. Cinquenta anos de industrialização baiana: do enigma a uma dinâmica exógena e espasmódica. Bahia Análise \& Dados, Salvador, Superintendência de Estudos Econômicos e Sociais da Bahia, v. 10, n. 1, p. 87-98, jul. 2000.

STAMM, C. et al. A população urbana e a difusão das cidades de porte médio no Brasil. Interações (Campo Grande), v. 14, n. 2, 2015. 


\section{Leonardo Rodrigues Porto}

Graduado em Ciências Econômicas pela Universidade Estadual do Sudoeste da Bahia (Uesb). Mestre em Desenvolvimento Econômico pelo Instituto de Economia da Universidade Estadual de Campinas (IE-Unicamp). Doutorando do Programa de Pós-graduação em Desenvolvimento Econômico do IE-Unicamp, na área de concentração em Desenvolvimento Regional e Urbano, vinculada ao Centro de Estudos do Desenvolvimento Econômico (CEDE) no mesmo instituto.

Email: Inrdporto@gmail.com

ORCID: 0000-0001-5296-2509

Contribuição de autoria: conceituação; curadoria de dados; análise formal; investigação/pesquisa; metodologia.

\section{Humberto Miranda}

Graduado em Ciências Econômicas pela Universidade Estadual de Feira de Santana (UEFS), mestre e doutor em Desenvolvimento Econômico pelo Instituto de Economia da Universidade Estadual de Campinas (IE-Unicamp). Professor do IE-Unicamp e pesquisador do Centro de Estudos do Desenvolvimento Econômico (CEDE) no mesmo instituto.

Email: humbmn@unicamp.br

ORCID: 0000-0001-5658-2909

Contribuição de autoria: conceituação; análise formal; investigação/pesquisa; metodologia.

Submissão: 30 de abril de 2020.

Aprovação: 16 de setembro de 2020.

Como citar: PORTO, L. R.; MIRANDA, H. O sistema urbano da Bahia no contexto da emergência de novas hierarquias urbano-regionais. Revista brasileira de estudos urbanos e regionais. v. 22, E202034, 2020. DOI 10.22296/2317-1529.rbeur.202034

Artigo licenciado sob Licença Creative Commons CC BY 4.0.

https://creativecommons.org/licenses/by/4.o/deed.pt_BR 